\section{STEM CELLS}

\section{How stem cells tell signal from noise}

Mouse stem cells switch on a neural developmental program when the activity of a specific gene lasts for a certain length of time.

Cells are flooded with many signals from gene expression. To find out how cells pick out the important ones from the background noise, Matt Thomson and his colleagues at the University of California, San Francisco, engineered mouse embryonic stem cells so that the Brn2 gene turned on when it was exposed to light. When the activity of this gene reached a specific duration and level, the stem cells rapidly began specializing into neural progenitor cells.

Mathematical modelling showed that a positive feedback network in the Brn 2 circuitry helps to ensure that the $\mathrm{Brn} 2$ signal rises above the noise. Cell Systems 1, 117-129 (2015)

\section{METEOROLOGY}

\section{Big coastal} storms to come

Three major coastal cities on different continents could get walloped by tropical cyclones during the next century because of climate change.

Ning Lin of Princeton University in New Jersey and Kerry Emanuel of the Massachusetts Institute of Technology in Cambridge ran statistical models of how storms form near the cities of Dubai, Cairns in Australia and Tampa, Florida - all of which are vulnerable to rising sea levels. With climate change, storm surges could reach as high as 6 metres in Dubai during the next 100 years; the city has never experienced a tropical cyclone. Storm surges would be slightly lower in Cairns and Tampa, but still greater than the levels those cities have seen before.

The authors calculate that by the end of the century, the annual probability of such powerful storms in Tampa would increase from about 1 in 10,000 now to between 1 in 2,500 and 1 in 700 .

Nature Clim. Change http://dx.doi. org/10.1038/nclimate2777 (2015)

\section{POPULATION BIOLOGY}

\section{Cane toads wage chemical war}

Invasive toads in Australia could be turned against each other to control the population.

Richard Shine at the University of Sydney in Australia and his colleagues grew cane toad (Rhinella marina) tadpoles and embryos together in containers in the laboratory, and separated them with a mesh partition. They found that the tadpoles suppressed embryo growth by $33-84 \%$ and reduced their survival to less than $5 \%$.

The tadpoles seem to produce a chemical that blocks embryo growth, allowing them to outcompete the embryos. The practice of removing tadpoles from breeding ponds could actually boost the growth of embryos; instead, tadpoles could be kept in mesh containers in the pond to stymie the embryos' growth, the authors say.

J. Appl. Ecol. http://doi.org/635 (2015)

\section{OBESITY}

\section{Genetic switch stores up fat}

A variation in a genetic region associated with obesity causes fat to be stored rather than burned.

Melina Claussnitzer at the Beth Israel Deaconess Medical Center in Boston, Massachusetts, Manolis Kellis at the Massachusetts Institute of Technology in Cambridge and their colleagues studied fat cells from 52 people with a version of the FTO genetic region that is associated with obesity and from 48 people with the non-risk version. The team found a single-nucleotide change in the risk-associated FTO region that boosted

SOCIAL SELECTION Ropmatopies

\title{
Lifetime collaborators reap benefits
}

Few researchers can do science single-handedly, making collaborations crucial. According to an analysis in Proceedings of the National Academy of Sciences, long-term collaborations pay big dividends, yielding a $17 \%$ boost in citation rate for resulting papers. Using a metric based on publications between collaborators over time, the analysis identified a group of strong partnerships, or 'super ties', that produced an unusually high number of papers in a given period. Papers from authors with such ties receive an average of 21 more citations in biology and 8 more citations in physics than those without a super tie. The findings were well received by observers on social media. "Collaboration works. Pick your collaborators carefully, they can stay with you for a long time," tweeted Wouter Gerritsma, an information specialist at Vrije University in Amsterdam. With those rewards in mind, Jeremy Borniger, a neuroscience $\mathrm{PhD}$ student at Ohio State University in DNATURE.COM Columbus, used Twitter to ask: "Who For more on wants to be my science life partner?" popular papers: Proc. Natl Acad. Sci. USA 112, E4671-E4680 go.nature.com/hkiong (2015)

expression of the genes $I R X 3$ and IRX5, which decreased the amount of energy burned and dissipated as heat. In fat precursor cells, this change resulted in the development of more energy-storing white fat cells and fewer energyburning beige fat cells.

Inhibiting Ir $x 3$ in mice caused the animals to lose weight without a change in appetite or exercise.

N. Engl. J. Med. http://doi.org/6z5 (2015)

Apes get by in
degraded habitat

Endangered chimpanzees could be adapting to landscapes that have been broken up by human activity.

Eastern chimpanzees (Pan troglodytes schweinfurthii) were thought to exist in low numbers in an area of Uganda where forest has been fragmented by farms and villages (pictured). Maureen McCarthy and Linda Vigilant of the Max Planck Institute for Evolutionary Anthropology in Leipzig, Germany, and their colleagues collected and genetically analysed hundreds of chimp droppings from about 630 square kilometres of fragmented habitat. They estimate that some 260 chimps in 9 communities live in about 1,200 square kilometres of what seems to be marginal habitat at best - more than 3 times the number of chimps that were previously estimated to live in this habitat.

The authors suggest that these and other rare species might be more adaptable - at least in the short term - than was thought.

BMC Ecol. http://doi.org/66q (2015)

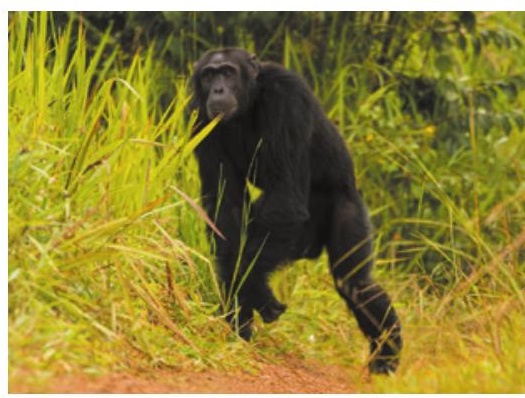

\section{$\rightarrow$ NATURE.COM}

For the latest research published by Naturevisit:

www.nature.com/latestresearch 